\title{
Design and Testing Servomotor Prototype
}

\author{
B. Nguyen Duc ${ }^{1,2 *}$, V. Tran Tuan ${ }^{1}$, C. Nguyen The \\ ${ }^{1}$ Hanoi University of Science and Technology, Hanoi, Vietnam \\ ${ }^{2}$ National University of Civil Engineering, Hanoi, Viet Nam \\ *Email: bacnd@nuce.edu.vn
}

\begin{abstract}
This paper proposes an optimal design "modern" approach for servomotors. This approach consists of the optimization algorithms at the initial analytical calculations and the modelling of the virtual prototype in order to reduce the costly and time-consuming prototyping loops of the "conventional" design method. The optimal design of a servomotor for robot application is verified by using finite element analysis (FEA) in terms of torque at low to high speeds. The thermal simulations based on lumped-mass model have been conducted in order to determine the operating duration of maximum and continuous performances of this machine. $A$ prototype of asynchronous servomotor is manufactured and tested in the test-bench. Experimental results of electromagnetic (torque) and thermal (rising temperatures of different positions in the motor) measurements of peak and continuous performances at different speeds will validate the virtual prototype as well as this design method.
\end{abstract}

Keywords: Servomotor, robot, optimal design, finite element analysis, prototype, testing

\section{Introduction}

Servomotors operate in a wide speed - high torque range, fast dynamics, positioning with high precision, short acceleration time, low weight, compact design. Thus, the reduction of mass of the servomotor by keeping the high torque during the design step not only reduces the production costs but also contributes to better dynamics (with the help of small moment of inertia), while guaranteeing the motor specifications.

Motor design in general, as well as servomotor design in particular, rely on virtual prototypes to reduce the time and cost of producing and testing prototypes, for example, prototype models are created using the finite elements method [1]. However, in order to achieve the desired technical requirements, the problem of optimal design in terms of shape and size is a difficult and complicated task when choosing the optimal parameters under constraints $[2,3]$. Companies are interested in reducing the manufacturing costs of motors by analysing and optimizing products [4].

The motor optimization design method proposed in [5-6], through the methodology using optimization algorithms. When optimizing an electric motor, there are multi-objectives [7-10], such as maximizing torque, minimizing mass or cost, however these goals are conflict with each other.

Today, servomotors (Fig. 1) are present in many drive system applications such as metal cutters,

ISSN 2734-9373

https://doi.org/10.51316/jst.150.ssad.2021.31.1.16

Received: February 8, 2021; accepted: May 24, 2021 conveyors, automatic door openers, robots, electric vehicles ... [4], [11-13]. When working over a wide torque speed range, to ensure small energy dissipation, the calculation and adjustment of the energy control parameters to achieve the best performance at each operating point is very important. In practice, the motor can operate at huge losses in the case that the setting of the energy control parameters is not optimal.

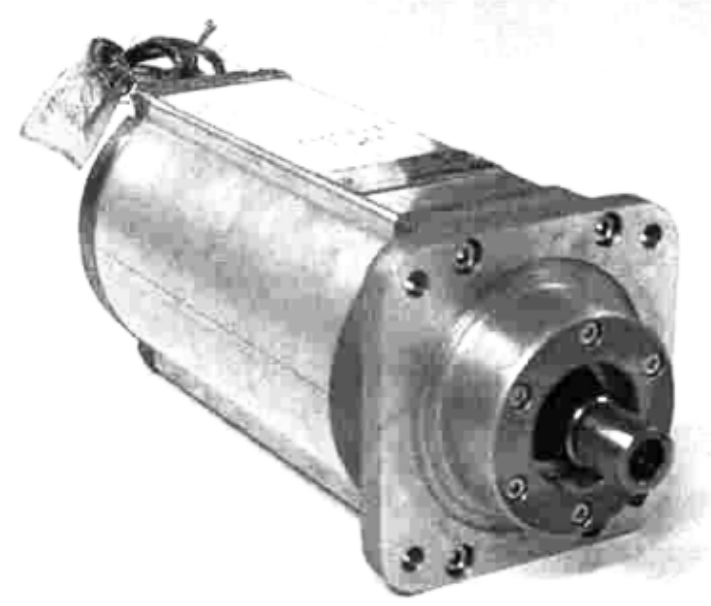

Fig. 1. Permanent magnet servomotor [11]

First, the paper will present the optimal design for servomotors in Section 2. Then, the manufacturing and testing of an asynchronous servomotor prototype will be detailed in Section 3. The comparison of simulation and measurement results is also analysed in this section. Finally, conclusions will be discussed in Section 4. 


\section{Optimal Design for Servomotors}

\subsection{Application of Servomotors in Industrial Robots}

Industrial robots are widely used today, performing work such as welding, machine maintenance, handling, grinding, packaging and assembly [14]. The current general trend in the industrial robot market is to regularly release new models with high precision and reasonable price. This leads to the need to reduce costs and develop new optimal products. The electric drive system is an important part of the robot, the main component being the servomotor. Optimal servomotor design is therefore essential for manufacturers of industrial robots. A typical drive cycle for a servomotor in industrial robots usually consists of the phases of acceleration, constant speed, deceleration and complete stop. Motors for this application are generally permanent magnet synchronous machines and limited in thermal behaviour [15]. The motor must deliver high torque throughout the cycle, but for only a fraction of the duty cycle, the average duty cycle loss is low. The thermal motor time constant is much higher than that of a drive cycle, so the average loss per cycle can be used to determine the required motor parameters. Therefore, the maximum torque during the drive cycle can be much higher than the rated torque of the motor. By determining the size of the motor, taking thermal responses into account, and designing the motor with maximum torque throughout the cycle, it is possible to optimize the motor for the required application [11].

Fig. 2 shows the robot arm joint $\mathrm{ABB}$ using the permanent magnet synchronous servomotor.

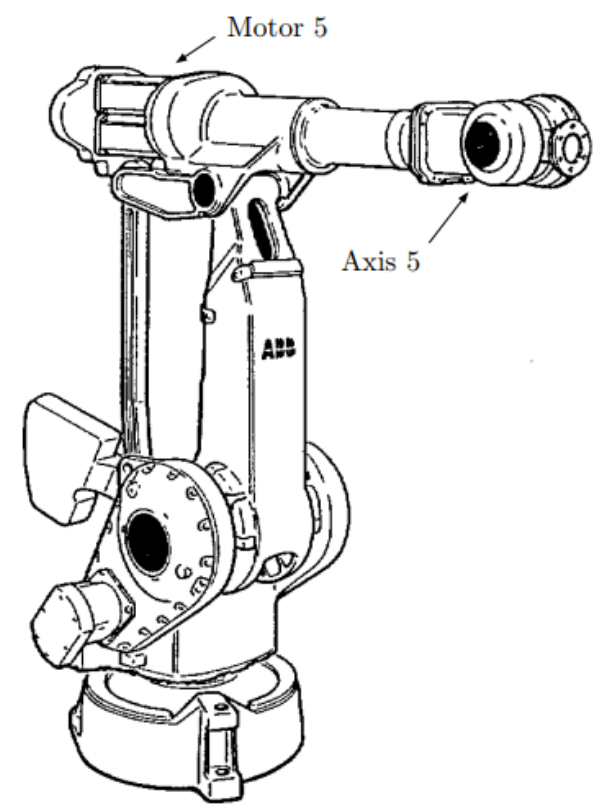

Fig. 2. Servomotors used for the robot arm joint [11]

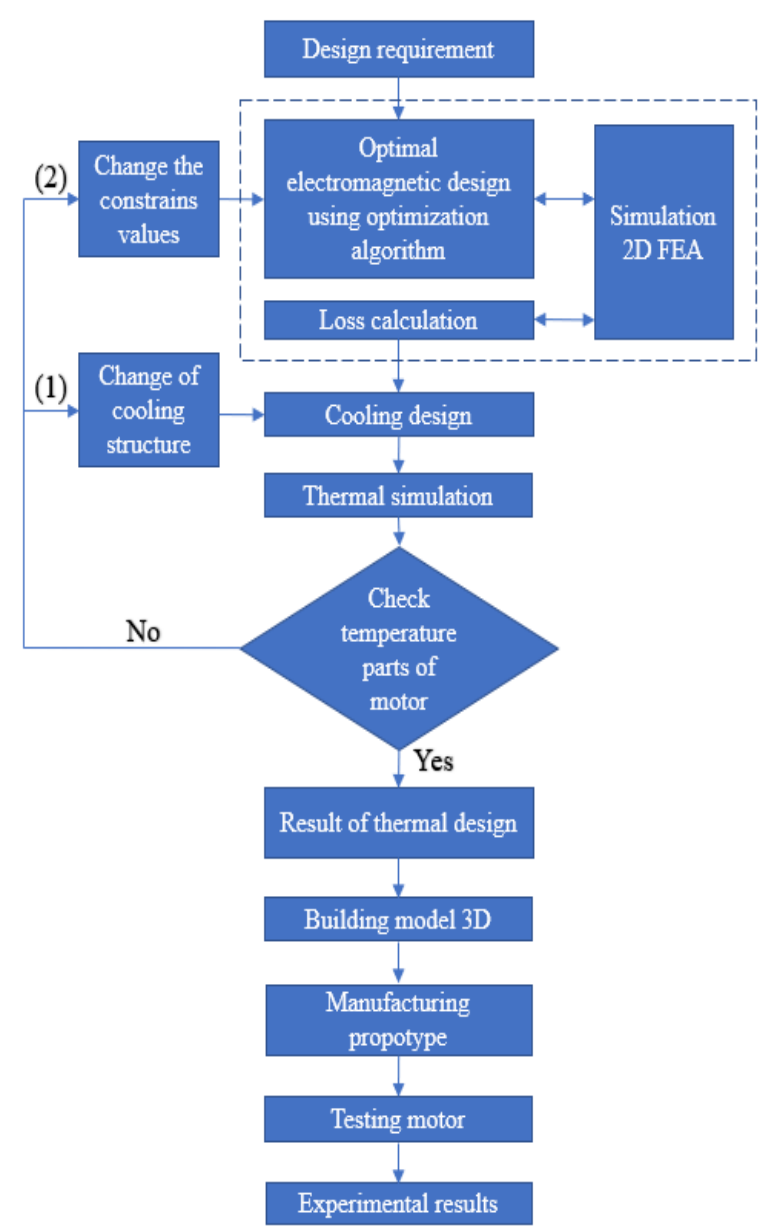

Fig. 3. Flowchart of the proposed optimal design for servomotors

\subsection{Design Flowchart}

To handle the specification of servomotor, a flowchart of the optimal design for servomotors can be proposed in Fig. 3 .

In the first step, the electromagnetic design is obtained using optimization algorithms under constraints coupling to a fast analytical model. This design is then verified by finite element analysis simulations giving more accurate results but having much higher computational time. In the second step, the thermal simulations are performed with cooling design architecture and losses from the previous step. If the temperature of one or several parts in the motor exceeds the limit value, the cooling system needs to be further optimized or changed. If it is not yet satisfied, we need to negotiate to change the multidisciplinary constraints (i.e. reduce the current density, reduce iron loss by changing electrical steel material, increase the volume, etc.) in the electromagnetic optimization design phase. The next step consists to build a 3D complete model of the motor and proceed the manufacturing prototype. The prototype will be tested and measured at different operating points in torque-speed range. Experimental 
results allow to verify and validate the optimal design of servomotor as well as the virtual prototype (thermal-electromagnetic models).

\subsection{FEA Simulation}

Finite element analysis aims to calculate characteristics of servomotor, such as density of flux, inductance, torque, etc, that allows to verify the optimal design of asynchronous servomotor obtained in [13]. In FEA, the magnetic circuit is modelled by a mesh of elements [16]. The values are then assumed to be magnetic functions of positioning within these elements, allowing the results to be interpolated. FEA provides detailed information about the nonlinear motor effects (based on geometry and material properties). This modelling approach is capable of obtaining an accurate and complete description of the electric motor. Fig. 4 shows the FEA 2D transient simulation, the maximum torque at $n=500 \mathrm{rpm}$. The average torque result obtained at this point is

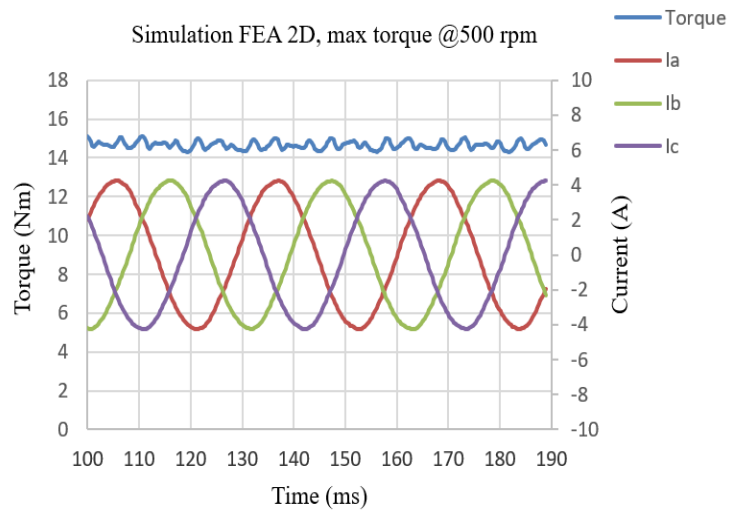

Fig. 4. Maximum torque and currents at $500 \mathrm{rpm}$ by 2D FEA simulation

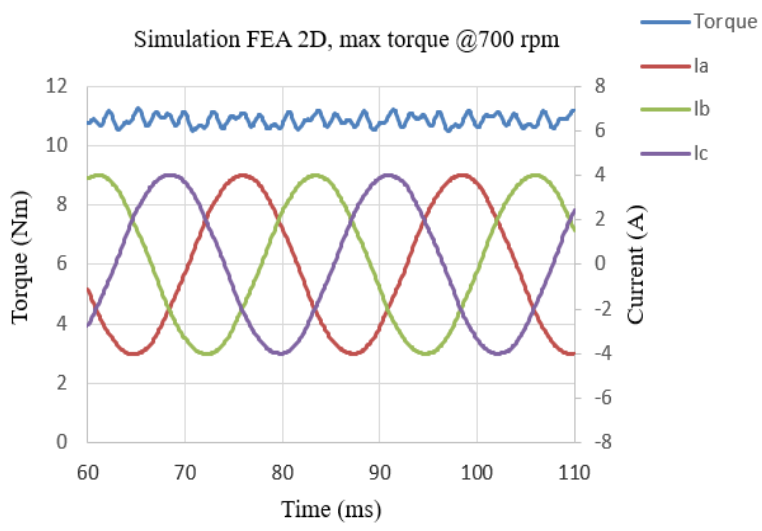

Fig. 6. Maximum torque and currents at $700 \mathrm{rpm}$ by $2 \mathrm{D}$ FEA simulation
14.7 Nm, with the maximum current allowed of 2.98 Arms, the gap of $2.0 \%$ compared to the optimal analytical design result [13].

Fig. 5 presents a map of flux density in FEA 2D simulation at this peak torque operating at $500 \mathrm{rpm}$. The saturated induction value is observed in the stator teeth at about 1.7 Tesla.

The maximum torque characteristic at higher speed, $n=700 \mathrm{rpm}$ is shown in Fig. 6. The average torque achieved is $10.9 \mathrm{Nm}$ with a current $2.82 \mathrm{Arms}$. At this operating point, the servomotor is already working in the field weakening area.

The torque characteristic at high speed, $n=3500 \mathrm{rpm}$ is shown in Fig. 7. The average torque achieved is $0.43 \mathrm{Nm}$, compared with the optimal analytical design, the obtained torque is $0.45 \mathrm{Nm}$, comparing to the optimal analytical design [13], the gap of $4.4 \%$.

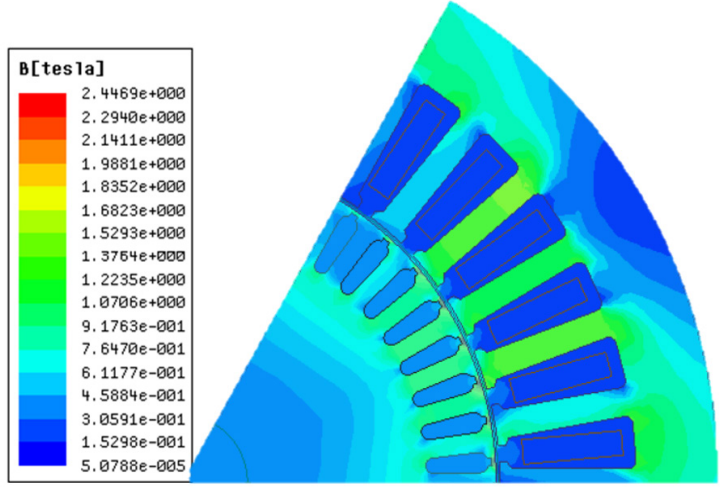

Fig. 5. Map flux density of $2 \mathrm{D}$ design machine at peak torque at $500 \mathrm{rpm}$

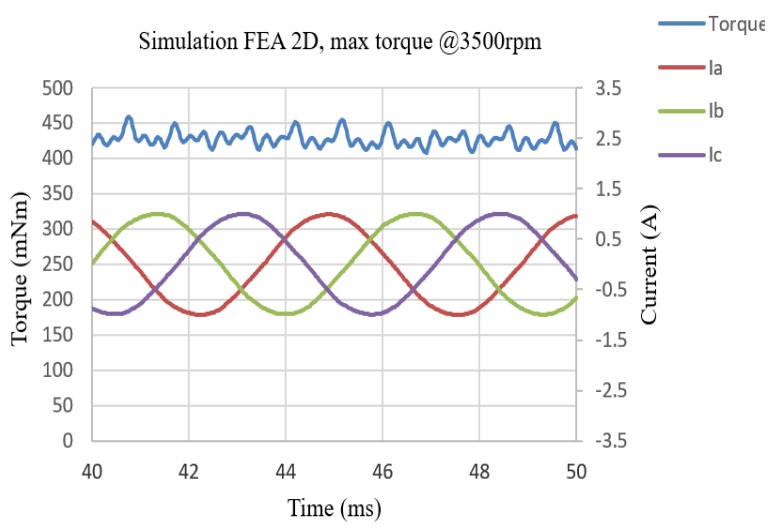

Fig. 7. Maximum torque and currents at $3500 \mathrm{rpm}$ by 2D FEA simulation 
JST: Smart Systems and Devices

Volume 31, Issue 1, May 2021, 124-131

Table 1. Main parameters of asynchronous servomotor prototype

\begin{tabular}{|l|c|c|}
\hline \multicolumn{1}{|c|}{ Main results } & Unit & Optimum \\
\hline Total mass of motor & $\mathrm{kg}$ & 12.5 \\
\hline Stator/rotor slots & - & $36 / 48$ \\
\hline Number of poles & - & 6 \\
\hline Total length of motor & $\mathrm{mm}$ & 180 \\
\hline Housing outer diameter & $\mathrm{mm}$ & 143 \\
\hline Number of turns & - & 105 \\
\hline Maximum voltage & $\mathrm{Vrms}$ & 380 \\
\hline Maximum current & Arms & 3.0 \\
\hline Maximum torque & $\mathrm{Nm}$ & 15.0 \\
\hline
\end{tabular}
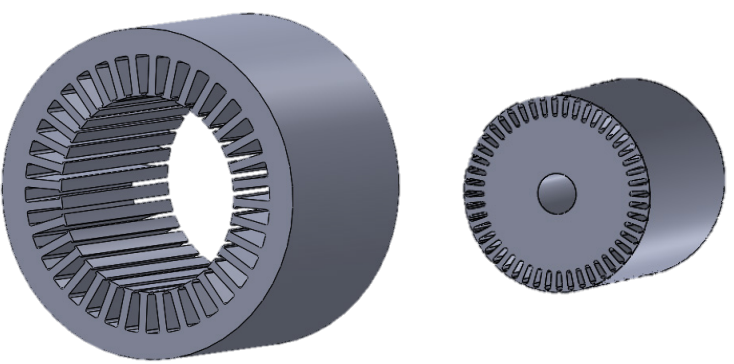

Fig. 8. Stator/rotor 3D model

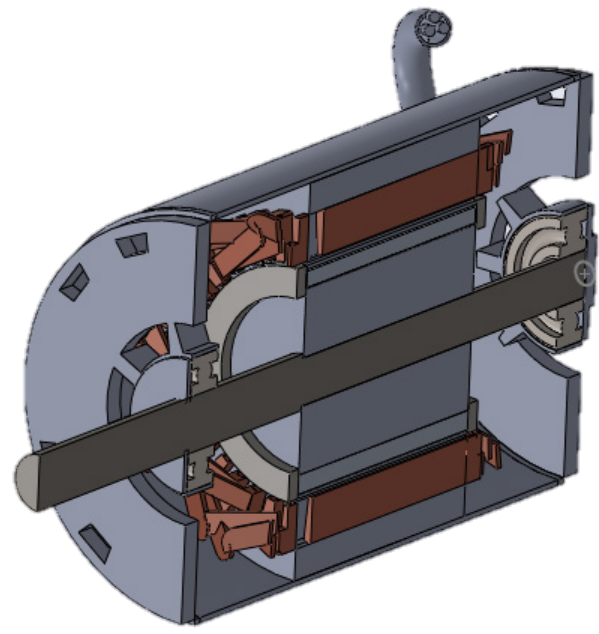

Fig. 9. Servomotor 3D full model

\section{Manufacturing and Testing of Prototype}

\subsection{The 3D Prototype Model}

The main parameters of this servomotor design are detailed in Table 1 . With a suitable minimum electromagnetic mass of $9.52 \mathrm{~kg}$ [13], the obtained design motor can provide a peak torque of $15.0 \mathrm{Nm}$ (limited by current constraint of $3 \mathrm{~A}$ ).
The stator/rotor 3D shapes (Fig. 8) and a completed 3D model of the optimal design are built using Solidwork package software (Fig. 9).

Fig. 10 shows the manufactured asynchronous machine prototype. The prototype is manufactured as a squirrel cage rotor asynchronous 3-phases servomotor. The magnetic circuit is realized from electrical steel laminations using a laser cutting method. The rotor cage is die-casted with aluminium material.

\subsection{Experiment}

The prototype servomotor is tested at test-bench in Hanoi Electromechanical Manufacturing Joint Stock Company (HEM), (Fig. 11). The capability of the test-bench system is:

- The load machine can run with a maximum torque/power of $50 \mathrm{Nm} / 15 \mathrm{~kW}$;

- The system allows to adjust the voltage in the range $[0: 380 \mathrm{~V}]$ $60 \mathrm{~Hz}]$.

- The frequency can be turned in the range [32 :

The experimentation testing results at the shortterm operating point at speed $n=500 \mathrm{rpm}$, voltage $U=361.8 \mathrm{~V}$, frequency $f=32 \mathrm{~Hz}$ (point), with the same current 3 Arms, the maximum torque reaches $14.6 \mathrm{Nm}$ (Fig. 12), a small gap of $0.7 \%$ comparing to FEA results.

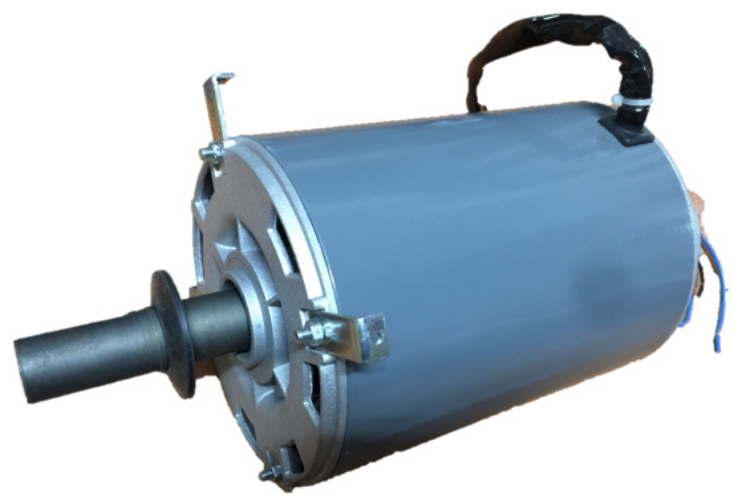

Fig. 10. Servomotor prototype

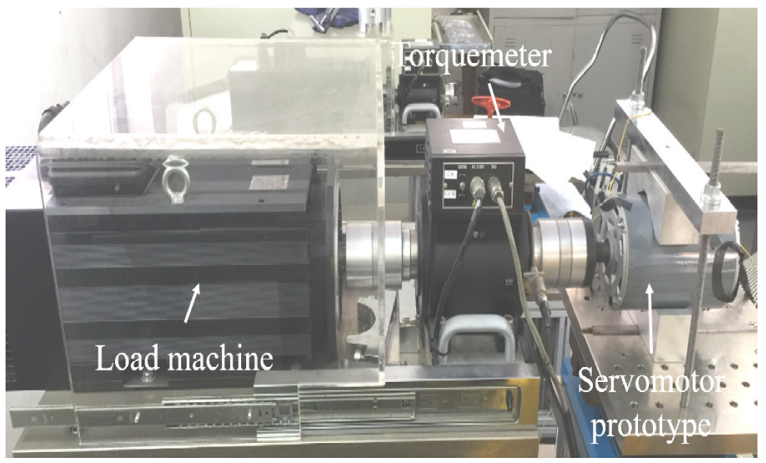

Fig. 11. Servomotor prototype tests on test-bench 


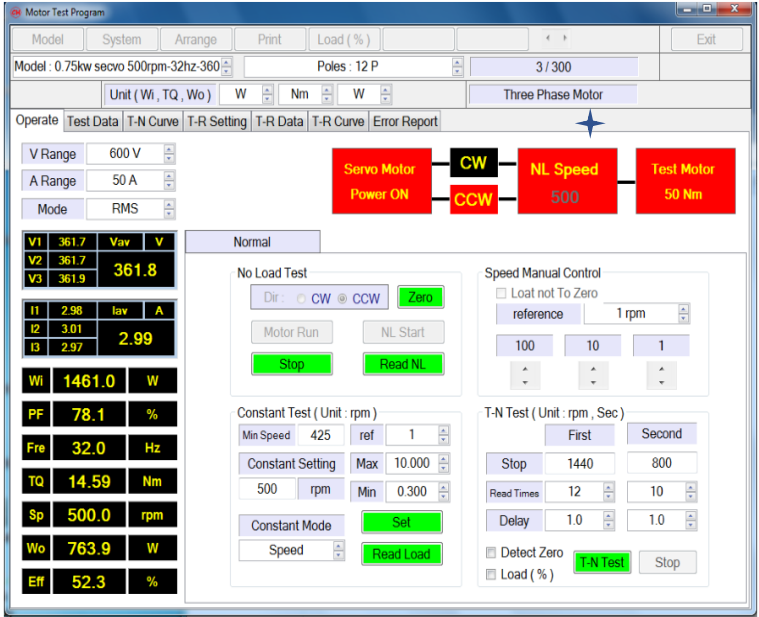

Fig. 12. Test results of motor parameters at $500 \mathrm{rpm}$, short-term mode

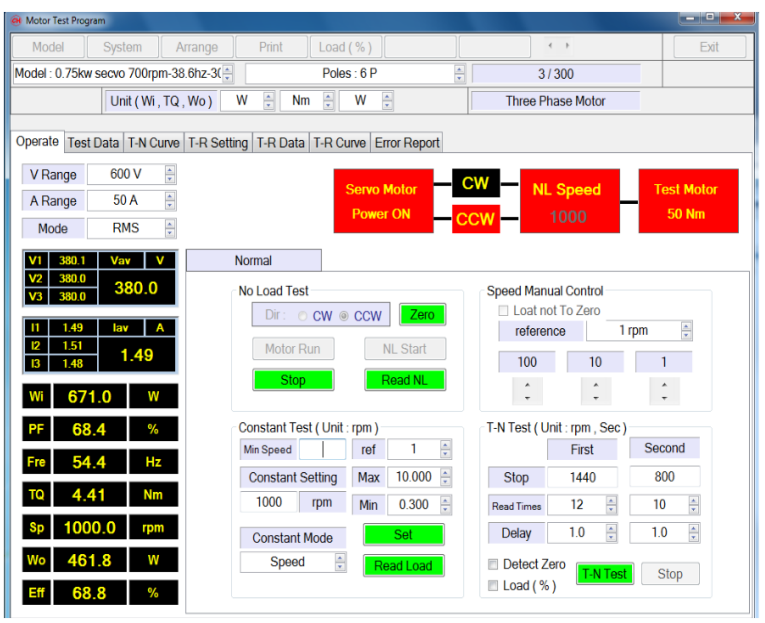

Fig. 13. Test results of motor parameters at $1000 \mathrm{rpm}$, long-term mode

The experimentation testing results at the longterm operating point at speed $n=1000 \mathrm{rpm}$, voltage $U=380 \mathrm{~V}$, frequency $f=54.4 \mathrm{~Hz}$ ), the motor produces the torque of $4.4 \mathrm{Nm}$ (Fig. 13), the gap with FEA results is $2.2 \%$.

Fig. 14 and Fig. 15 present the tuning of optimal control parameters (voltage and frequency). Fig. 14 shows the torque characteristic at $700 \mathrm{rpm}$ by sweeping the frequencies from 37 to $59 \mathrm{~Hz}$. At voltage $U=350 \mathrm{~V}$, the torque is maximum of $9.82 \mathrm{Nm}$, at frequency $f=47.1 \mathrm{~Hz}(I s=2.58 \mathrm{~A})$. When the voltage $U=380 \mathrm{~V}$ (Fig. 15), if the frequency increases, the current in the stator winding increases, the maximum torque reaches $11.3 \mathrm{Nm}$, at $f=46 \mathrm{~Hz}$ and then decreases. Finally, the optimal torque is maximized at $U=380 \mathrm{~V}$, frequency $f=46 \mathrm{~Hz}$, reaching 11.3 $\mathrm{Nm}(I s=2.69 \mathrm{~A})$ (Fig. 16), because the stator voltage constraint $U \leq 380 \mathrm{~V}$. The torque gap comparing to simulation is $3.5 \%$.

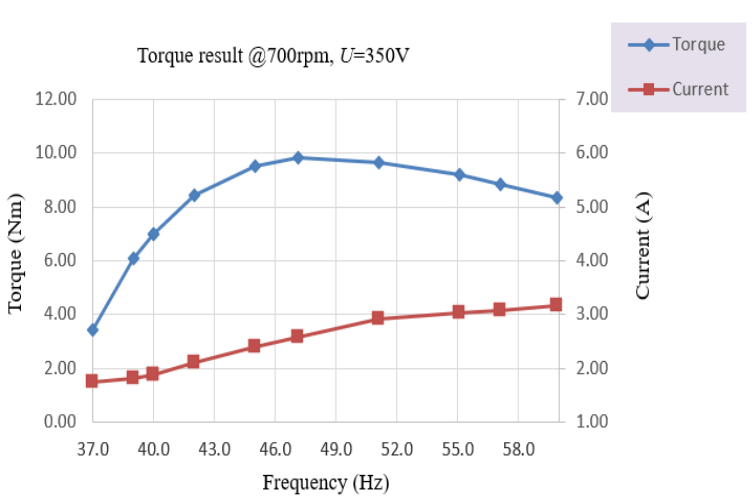

Fig. 14. Torque characteristic according to frequency at $n=700 \mathrm{rpm}, U=350 \mathrm{~V}$

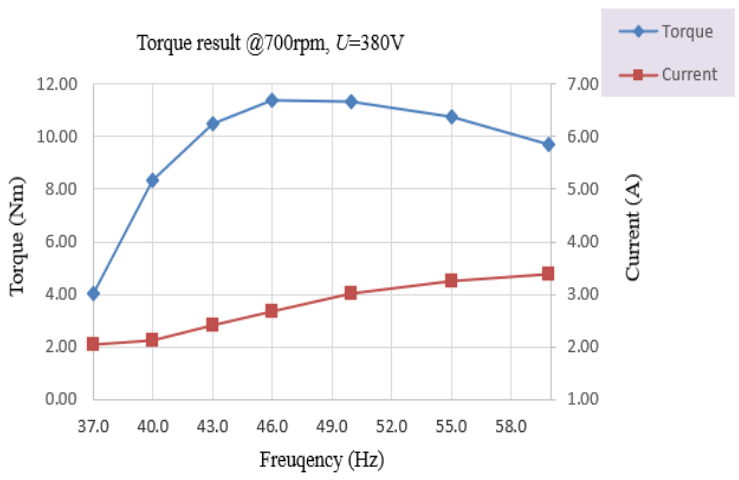

Fig. 15. Torque characteristics according to frequency at $n=700 \mathrm{rpm}, U=380 \mathrm{~V}$

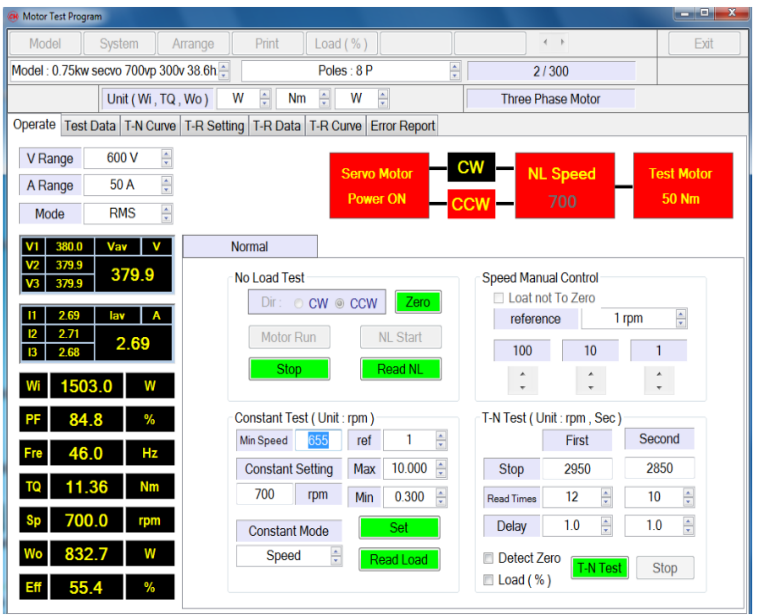

Fig. 16. Test results of motor parameters at $700 \mathrm{rpm}$, short-term mode

Similarly, when comparing the test results of other operating points, the gap compared to the simulation results is all less than $5 \%$ (Table 2). At the operating points on the maximum characteristic curve, because the motor only works for a short time, and the torque depends on the temperature, the gap between measurement and simulation is quite larger than when testing at continuous operating points. The 
experimental results show that the optimal motor design model is completely consistent.

Fig. 17 shows the torque-speed characteristics and the results of the motor torque measurement test at several peaks and continuous operating points $(\bullet)$. The results show that the gap between the experimental and the model is small and less than $5 \%$.

Table 2. Comparison between simulation and experimentation results

\begin{tabular}{|c|c|c|c|}
\hline Parameters & Simulation & $\begin{array}{l}\text { Experiment } \\
\text {-ation }\end{array}$ & $\begin{array}{r}\text { Gap } \\
(\%)\end{array}$ \\
\hline \multicolumn{4}{|l|}{ At $500 \mathrm{rpm}$ - peak } \\
\hline Torque (Nm) & 14.7 & 14.6 & 0.7 \\
\hline Current (A) & 2.98 & 2.99 & 0.3 \\
\hline Frequency (Hz) & 32.0 & 32.0 & 0.0 \\
\hline Voltage (V) & 360 & 361.8 & 0.5 \\
\hline \multicolumn{4}{|l|}{ At $700 \mathrm{rpm}$ - peak } \\
\hline Torque (Nm) & 10.9 & 11.3 & 3.5 \\
\hline Current (A) & 2.82 & 2.69 & 4.8 \\
\hline Frequency (Hz) & 44.5 & 46.0 & 3.2 \\
\hline Voltage (V) & 380 & 379.9 & 0.1 \\
\hline \multicolumn{4}{|c|}{ At $700 \mathrm{rpm}$ - continuous } \\
\hline Torque (Nm) & 4.6 & 4.7 & 2.1 \\
\hline Current (A) & 1.51 & 1.55 & 2.5 \\
\hline Frequency $(\mathrm{Hz})$ & 38.8 & 38.6 & 0.5 \\
\hline Voltage (V) & 300.0 & 299.5 & 0.2 \\
\hline \multicolumn{4}{|c|}{ At $1000 \mathrm{rpm}$ - continuous } \\
\hline Torque (Nm) & 4.5 & 4.4 & 2.2 \\
\hline Current (A) & 1.51 & 1.49 & 1.3 \\
\hline Frequency $(\mathrm{Hz})$ & 54.6 & 54.4 & 0.4 \\
\hline Voltage (V) & 380.0 & 380.0 & 0.0 \\
\hline
\end{tabular}

Six temperature sensors are instrumented to measure the ambient, stator windings, both covers and motor housing. The results of temperature measurement of the motor at the peak operating point at speed $n=500 \mathrm{rpm}$, and $14.6 \mathrm{Nm}$ (Fig. 12) are shown in Fig. 18. The ambient temperature is $23{ }^{\circ} \mathrm{C}$. The running test motor is stopped when the winding temperatures reach approximately $116{ }^{\circ} \mathrm{C}$, the short run duration is recorded at $546 \mathrm{~s}(9.1 \mathrm{~min})$. These thermal results show that the design servomotor can work comfortably at maximum torque in a short-time or it can produce more torque if we can allow a higher current ( $>3$ Arms)

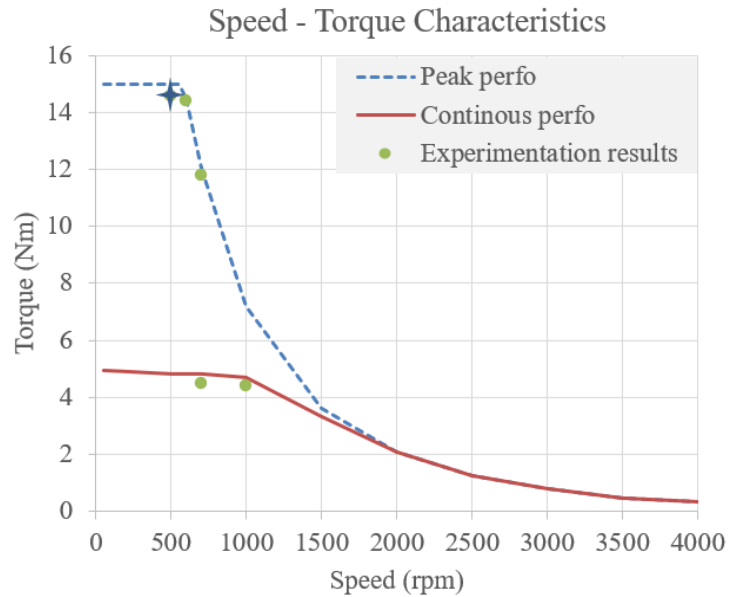

Fig. 17. Torque - speed characteristics of the design servomotor and measurement results

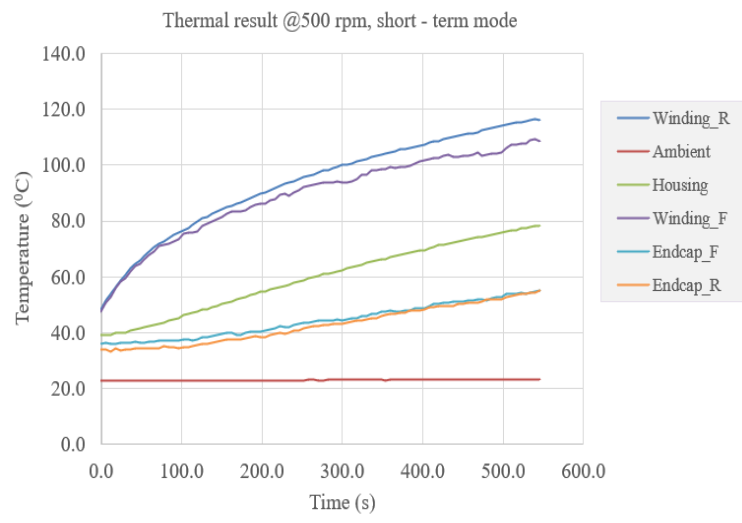

Fig. 18. Test results of motor servo at $500 \mathrm{rpm}$, shortterm mode

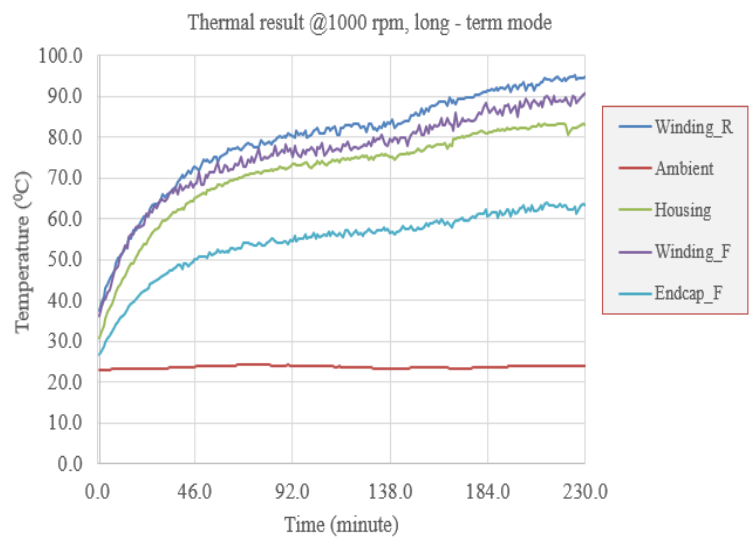

Fig. 19. Test results of motor servo at $1000 \mathrm{rpm}$, long-term mode

The results of temperature measurement of the motor at the continuous operating point, $n=1000 \mathrm{rpm}$ and 4.4 N.m, are shown in Fig. 19 . After 3.8 hours, the temperatures in the servomotor 
prototype are stabilized, $95^{\circ} \mathrm{C}$ for the stator winding, $82{ }^{\circ} \mathrm{C}$ for the housing, $63{ }^{\circ} \mathrm{C}$ for the endcap. We can choose the insulation class $\mathrm{A}$ for the winding, or if this servomotor can perform more continuous performance when choosing the class $\mathrm{E}\left(120^{\circ} \mathrm{C}\right)$.

\section{Conclusion}

This paper has proposed a modern design method for asynchronous servomotor, using optimization algorithm from the initial calculation, combining virtual prototype model and optimal control parameters. The optimal design results are verified by FEA simulation. The servomotor prototype is manufactured, according to this optimal design. For the test results at the peak operating point of $500 \mathrm{rpm}$, voltage $361.8 \mathrm{~V}$, frequency $32 \mathrm{~Hz}$, the motor torque reached $14.6 \mathrm{Nm}$. At this operating point, the servomotor can handle this peak operating point during 9 minutes with the limitation of stator winding of $120^{\circ} \mathrm{C}$. The temperature measurement of the motor at the continuous operating point at $1000 \mathrm{rpm}$ and $4.4 \mathrm{Nm}$, with heat saturation time is 3.8 hours. The saturation temperature in stator winding is only $95{ }^{\circ} \mathrm{C}$. The experimental results of the prototype demonstrate that the proposed optimal design method and the virtual prototype are suitable. This design method can be applied to other servomotors with different application requirements.

\section{Acknowledgments}

The authors would like to thank Hanoi Electromechanical Manufacturing Joint Stock Company for supporting the testing of the prototype servomotor for this study.

The authors would like to thank Advantech JSC (ADT) for providing Ansys Maxwell software for supporting this study.

\section{References}

[1] Fitouri, M., BenSalem, Y., \& Abdelkrim, M. $\mathrm{N}$., Analysis and co-simulation of permanent magnet synchronous motor with short-circuit fault by finite element method. 2016 13th International MultiConference on Systems, Signals \& Devices (SSD) (2016).

https://doi.org/10.1109/SSD.2016.7473721

[2] M. Centner, Basics and application of motor design optimization in an industrial environment. 21th International Conference on, Electrical Machines (ICEM), in Berlin, Germany, (2014) 1008-1012. https://doi.org/10.1109/ICELMACH.2014.6960304

[3] S. Stipetic, W. Miebach, D. Zarko, Optimization in design of electric machines: Methodology and workflow. Aegean Conference on Electrical Machines and Power Electronics and Advanced Electromechanical Motion Systems (ACEMPOPTIMELECTROMOTION), Side, Turkey (2015) 441-448.

https://doi.org/10.1109/OPTIM.2015.7427030
[4] Damir Zarko, Drago Ban, Davor Gooricki, Improvement of a servomotor design including optimization and cost analysis. 12th International conference on Power Electronics and Motion Control Conference (EPE-PEMC), in Portoroz, Slovenia, (2006) 302-307. https://doi.org/10.1109/EPEPEMC.2006.283097

[5] Mehmet Çunkaşa, Ramazan Akkayab, Design optimization of induction motor by genetic algorithm and comparison with existing motor, Mathematical and Computational Applications, Vol. 11, No. 3, (2006) 193-203.

https://doi.org/10.3390/mca11020193

[6] Li, S., \& Yang, M. Particle swarm optimization combined with finite element method for design of ultrasonic motors. Sensors and Actuators A: Physical, 148(1), (2008) 285-289.

https://doi.org/10.1016/j.sna.2008.08.004

[7] Akundi, S. V. K., Simpson, T. W., \& Reed, P. M, Multi-objective design optimization for product platform and product family design using genetic algorithms. 31st Design Automation Conference, Vol 2 (2005).

https://doi.org/10.1115/DETC2005-84905

[8] Wu, S., Yu, B., Jiao, Z., Shang, Y., \& Luk, P, Preliminary design and multi-objective optimization of electro - hydrostatic actuator. Proceedings of the Institution of Mechanical Engineers, Part G: Journal of Aerospace Engineering, 231(7), (2016) 1258-1268. https://doi.org/10.1177/0954410016654181

[9] A. Messac, A. Ismail-Yahaya, The normalized normal constraint method for generating the Pareto frontier. Struct. Multidiscipl. Optim, Vol 25, (2003) 86-98. https://doi.org/10.1007/s00158-002-0276-1

[10] R.T. Marler, Survey of multi-objective optimization methods for engineering. Struct. Multidiscp. Optim., Vol 26 (2004) 369-395. https://doi.org/10.1007/s00158-003-0368-6

[11] Andersson S, Optimization Servo Motor for Industrial Robot Application, Lund University, Sweden (2000).

[12] Vu Tran Tuan, Sangkla Kreuawan, Pakasit Somsiri, Kanokvate Tungpimolrut, Phuong Nguyen Huy, Switched reluctance motor and induction machine for e-scooter based on driving cycles design comparisons. IEEJ Transactions electrical and Electronic Engineering, Vol 15 (2020) 931-938. https://doi.org/10.1002/tee.23136

[13] Nguyen Duc Bac, Tran Tuan Vu, Nguyen The Cong, Multi-target optimal design of servo motors by $\varepsilon$ constraint algorithm, Journal of Science \& Technology, Hanoi University of Industry, Vol 56, Issue 6, (2020) 26-30. (In Vietnamese). https://doi.org/10.31814/stce.nuce2019-13(1V)-06

[14] Padilla-Garcia, E. A., Rodriguez-Angeles, A., Resendiz, J. R., \& Cruz-Villar, C. A, Concurrent optimization for selection and control of $\mathrm{AC}$ servomotors on the powertrain of industrial robots. IEEE Access, Vol 6, (2018) 27923-27938. https://doi.org/10.1109/ACCESS.2018.2840537 
JST: Smart Systems and Devices

Volume 31, Issue 1, May 2021, 124-131

[15] Nguyen Duc Bac, Tran Tuan Vu, Nguyen The Cong, Nguyen Truong Giang, Themal simulations compare cooling structures for asynchronous servomotor. Journal of Military Science and Technology, Vol 71, (2021) 63-70. (In Vietnamese).

[16] O. Tikhonova, I. Malygin, và A. Plastun, Electromagnetic calculation for induction motors of various designs by 'ANSYS maxwell'. International Conference on Industrial Engineering, Applications and Manufacturing, ICIEAM 2017 - Proceedings, (2017) 1-4.

https://doi.org/10.1109/ICIEAM.2017.8076294 